\title{
Green synthesis of tin based nano medicine: Assessment of microstructure and surface property
}

\author{
Sethumadhavan Sudhaparimala ${ }^{1}$, Arumugam Gnanamani A. ${ }^{2}$, Asit Baran Mandal ${ }^{3, *}$ \\ ${ }^{1}$ Department of Chemistry, Ethiraj College for Women (Autonomous), Chennai - 8, India \\ ${ }^{2}$ Microbiology Division, Central Leather Research Institute (CSIR, New Delhi), Adyar, Chennai 20, India \\ ${ }^{3}$ Chemical Laboratory, Central Leather Research Institute, Adyar, Chennai (Madras) 600020, India

\section{Email address:} \\ sudha92@gmail.com (Sudhaparimala. S), gnanamani3@gmail.com (Arumugam G. A.), abmandal@hotmail.com (Asit B. M.), \\ abmandal@clri.res.in,clrim@vsnl.com (Asit B. M.), abmandalchem@yahoo.com (Asit B. M.)
}

\section{To cite this article:}

Sethumadhavan Sudhaparimala, Arumugam Gnanamani A., Asit Baran Mandal. Green Synthesis of Tin Based Nano Medicine: Assessment of Microstructure and Surface Property. American Journal of Nanoscience and Nanotechnology. Vol. 2, No. 4, 2014, pp. 75-83. doi: 10.11648/j.nano.20140204.13

\begin{abstract}
The present study is about an eco-friendly and cost effective method of using five potent plant extracts and sunlight as the reaction medium and grinding as a nano technique to prepare nano composite of tin (IV) oxide from tin metal. The equivalent preparation is widely used as a drug formulation in the treatment of spectrum of infectious diseases. The intensive grinding and calcinations with the plant material lead to the formation of nano crystallite with a tetragonal phase with an average crystallite size of $27 \mathrm{~nm}$. The elements $\mathrm{Ca}, \mathrm{P}, \mathrm{Na}, \mathrm{Mg}$ and $\mathrm{Fe}$ at the microscopic level identified at the surface of the nano crystallite by the X - ray Photo Electron Spectroscopy showed the uniqueness of the synthesis. The formation of spherical crystallites with good distribution of pores was indicated by the electron microscopic images and adsorption studies. The presence of oxygen deficiency arising due to nonstoichiometry in the crystal lattice was evident from the Electron paramagnetic Resonance study. The free radical equivalent of DPPH radical calculated for the final stage sample was suggestive of its anti-oxidant property and hence it's biological activity. The overall research study provided an alternative route of preparing nontoxic nano tin (IV) oxide composite with good biological activity apart from its already proven catalytic and sensor applications.
\end{abstract}

Keywords: Nanomedicine, Green Synthesis, Nano Tin (IV) Oxide Composite, Microstructure

\section{Introduction}

There is a growing demand for nano scale materials and there is a need for an integrative approach of conventional and advanced techniques of nano synthesis. Among the nano materials, those of metals and metal oxides are gaining greater significance due to their growing contribution in the chemical, electronic, pharmaceutical industries [1] Research reports on modern nano technology are many but are not cost effective and hence not affordable universally. In this context, green synthetic approach using plant extracts are widely explored owing to their simplicity and eco - friendly approach as shown by [2].

The bio molecules like alkaloids, flavones, terpenes, amino acids, carbohydrates present in the plant materials can act as reducing agents, capping agents, or can increase the rate of nano synthesis or the stability of the product.
There are many reports on the effect of plant materials playing a key role on the surface morphology and size of the metals [3].

Among the nano metal oxides, tin (IV) oxide is a versatile oxide having wider applications in the field of gas sensing and catalysis and as a transparent conducting oxide [4]. In all its above applications, its bulk structure, surface and interface properties play a key role. Apart from these applications, biological and medicinal applications have been reported recently for nano tin (IV) oxide, which gives new value addition to nano tin (IV) oxide. Triligio et al (2012) [5] reported the anti viral activity of nano tin (IV) oxide wires while, nano crystalline tin (IV) oxide was detected and fingerprinted in the tin based herbal formulations used for the treatment of range of chronic 
diseases [6,7].

There are many synthetic methods available for nano crystalline tin (IV) oxide. Some of the important methods are Sol - gel, Solvothermal, Electro chemical, Chemical Vapour and Pulsed Laser Deposition methods. But, a very few reports are available on its green synthesis. Among the green methods of preparations of nano tin (IV) oxide and its calcium salt, there are research reports by which were in the context of drug formulations for a range of chronic diseases.

The present study was carried out to find out the physico chemical changes during the processing, nature of the intermediates if any, and the final product obtained during the successive grinding with five different plant extracts and calcinations of metallic tin. The method of preparation was in the lines of Materia Medica [8] which was intended for the treatment of wide range of disease, viz:- Delirium, Tuberculosis, Ulcer The bio chemical properties of the plant extracts used in the present study namely, Tamarindus indica, Ficus bengalhensis , Baringtoria acutagularis, Annona Squamosa Linn, Cyclea peltata used in the present study are very significant $[9,10,11,12,13]$.

The product sample at the end of each step was subjected to the analyses in terms of material science and nano science. The final product of the synthesis namely, nano tin (IV) oxide were found to exhibit all the microstructural, surface and morphological properties required for its reported application as a $\mathrm{n}$ type semiconductor, sensor, and catalyst. In addition, a preliminary screening for antioxidant property of the product was also carried out to relate the structure with the (re)activity of the product. The study suggested a unique synthetic process of nano composite of tin (IV) oxide which has multi dimensional applications including the bio medical ones.

\section{Experimental}

The precursor of the process namely, metallic tin was obtained from Sigma Chemicals, India. The plants were obtained from the local farm garden. The pure white tin metal was powdered and triturated (ground with the plant extract intensively in pestle and mortar) with the freshly prepared leaf extracts of the plants in the ratio of 1:6 till a homogenous paste was formed and then sun dried till the sample was completely free from moisture and ready for calcinations. Then it was calcined at a running temperature of $400^{\circ} \mathrm{C}$. In step II, the calcined product of the step I was subjected to trituration with the second plant extract namely Ficus Benghalensis followed by calcinations. In a similar way the producr of step II, step III and step IV were subjected to trituration with plant extract of Baringtoria acutagularis, Annona Squamosa Linn, Cyclea Peltata respectively. The samples were collected at the end of each step I, II, III, IV, V and labelled as S1, S2, S3, S4, and S5 respectively.

\subsection{Analyses of Bulk and Surface Properties}

The structural aspects of the samples were studied in terms of bulk and surface properties. For FT-IR spectral analysis, sample was mixed with $\mathrm{KBr}$ (Sigma, US) and the pellet obtained after hydrolytic press, were analyzed using Spectrum one (Perkin-Elmer Co., USA model). All measurements consisted of 500 scans and the plain $\mathrm{KBr}$ pellet used as background reference. FT- Raman analysis was performed using FT Raman Bruker RFS/ 27 with a He: $\mathrm{Ne}$ Yag laser with a $100 \mathrm{~mW}$ of power (with a excitation wavelength of $1064 \mathrm{~nm}$ ) in a wavelength range of $50-$ $4000 \mathrm{~cm}^{-1}$ using a liquid nitrogen cooled Germanium as detector and Rock - Solid interferometer.

In the present study, Perkin-Elmer 5300DV ICP-OES was used for the quantitative determination of metallic elements. The percentage composition of $\mathrm{C}, \mathrm{N}, \mathrm{H}$ and $\mathrm{S}$ in the sample was determined using Elemental Analyser (Euro Vector model). Photoluminescence study of the sample was performed using Cary 100 (Varian) Fluorescence spectrophotometer. Thermo gravimetric analysis of the sample was made using TGA Q50 (V20.6 Build 31) and DSC analysis using DSC Q200 (V23.10 Build 79) at nitrogen atmosphere. Powder X-ray Diffraction (PXRD) patterns of the solid calcined sample was recorded using Rigaku Powder X-ray diffractometer with $\mathrm{Cu} / 30 \mathrm{KV} / 15 \mathrm{~mA}$ and a scan speed of $4 \mathrm{deg} / \mathrm{min}$ in $2 \theta$ range from 10 to 80 degrees with a sampling step of 0.05 deg. EPR spectra of the sample was recorded as a first derivative using Bruker EMX computer controlled spectrometer operating at Xband frequencies $(\sim 9.5 \mathrm{GHz})$ with a rectangular cavity.

The surface area of the nano crystalline samples and their adsorption properties were studied by BET analysis. The specific pore volume and distribution of pores in the samples were determined by Barrett - Joyner-Halenda (BJH) analysis.

The surface morphology of the samples was studied using Environmental Scanning Electron Microscope (ESEM) (Hitachi S 4000 voltage of $10 \mathrm{Kev}$ ). The relative elemental composition of the samples was computed directly with EDX software using ZAF correction. X-ray photoelectron spectroscopy (XPS) analysis was made using Kratos Axis 165 instrument with a dual anode (Mg and $\mathrm{Al}$ ) and $\mathrm{Mg}-K_{\alpha}$ anode. Morphology and the dimension of the crystalline samples were taken on a JEOL model $-200 \mathrm{cx}$ using an accelerating voltage of $120 \mathrm{kV}$.

\subsection{Preliminary Profile of the Anti Oxidant Property}

The antioxidant profile of the product was studied using EPR spectroscopy. Sample at $1 \mathrm{mg} \mathrm{ml}^{-1}$ concentration in ethanol was taken and the Di Phenyl Picryl Hydrazyl free radical $\mathrm{DPPH} \bullet$ concentration was fixed as $2 \mathrm{mM}$ in ethanol. The sample was added to $\mathrm{DPPH}^{*}$ and allowed to remain in equilibrium for 30 minutes. EPR signal of $\mathrm{DPPH}^{*}$ was recorded after the equilibrium was reached and the g-value was measured and the free radical equivalent was calculated from the double integrated spectrum. The absorption intensity as obtained from the double integrated 
spectrum was related to the free radical $\left(\mathrm{DPPH}^{\circ}\right)$ concentration.

\section{Results and Discussion}

The product was collected at the end of each calcinations step and then, the physical and morphological observations were made. The intensity of the flesh color observed in the first stage of the sample S1 progressively increased with stages and reasonable red tinge in the fifth stage sample S5 was observed. The results of the analytical study can be discussed as follows.

\subsection{Fourier-Transformed Infra Red Spectroscopic Analysis}

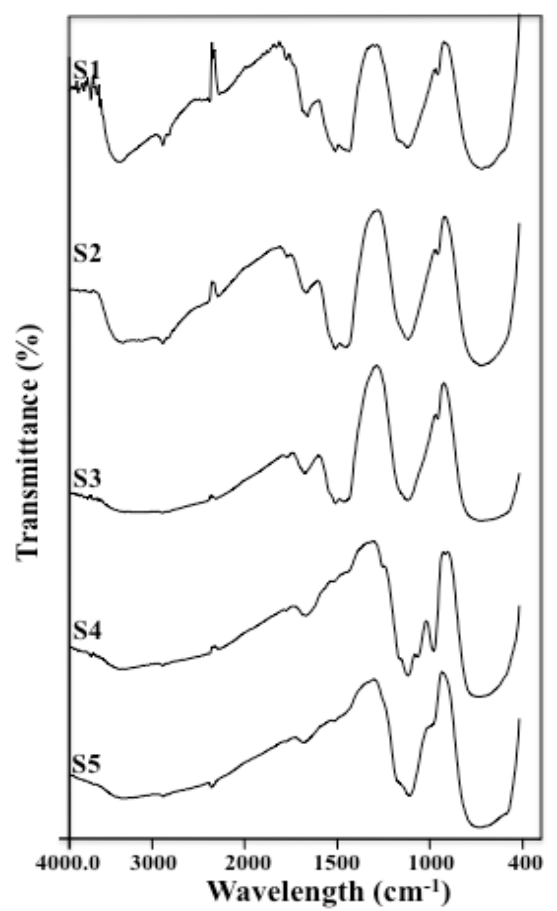

Figure 1. FT-IR spectrum of the nano tin (IV) oxide samples obtained during trituration of tin metal with five plant extracts followed by calcinations

Fig.1 illustrates the FT-IR spectrum of the samples S1 to S5. In all the samples, peaks were observed in the regions of $625-665 \mathrm{~cm}^{-1}$ and $1040-1060 \mathrm{~cm}^{-1}$ corresponding to O-Sn-O bridge of $\mathrm{SnO}_{2}$. The peak 1040-1060 $\mathrm{cm}^{-1}$, a characteristic of $\mathrm{Sn}=\mathrm{O}$ and $\mathrm{Sn}-\mathrm{O}$, indicates the presence of adsorbed oxygen species, intermediate between $\mathrm{O}_{2}^{-}$and $\mathrm{O}_{2}{ }^{2-}$. Also there was an additional peak of low intensity in the region $1460-1470$ and $865-870 \mathrm{~cm}^{-1}$ in the stages of I, II, and III indicated the presence of carbonates and it disappeared in stages of IV and V. The absence of peaks at 1450, 1088, and $850 \mathrm{~cm}^{-1}$ indicated the absence of inorganic carbonates [14]. In all the samples, except the final stage sample, there was a broad peak in the region
$3200-3500 \mathrm{~cm}^{-1}$ and around $1640 \mathrm{~cm}^{-1}$ confirming the presence of physisorbed water. In the final stage sample the peaks due to $-\mathrm{OH}$ stretching frequency was not intense enough. The FTIR spectra confirmed the formation of $\mathrm{SnO}_{2}$ from the first stage of preparation itself. The sharpness and intensity of the Sn-O-Sn characteristic peak indicated that $\mathrm{SnO}_{2}$ was the major constituent in all stages.

\subsection{Fourier-Transformed Raman Analysis}

The FT Raman spectrum of the final stage sample is shown in the Fig.2. The small intensity bands observed at $650 \mathrm{~cm}^{-1}$ in the purified tin metal was shifted to the region of $625-630 \mathrm{~cm}^{-1}$ in the calcined samples. The bands in the regions 628-630 $\mathrm{cm}^{-1}$ assigned to $\mathrm{A}_{1 \mathrm{~g}}$ mode of $\mathrm{SnO}_{2}$ rutile structure. There was a small hump in the region 770-790 $\mathrm{cm}^{-1}$ assigned to $B_{2 \mathrm{~g}}$ mode. There was absence of intense and broad band at $571 \mathrm{~cm}^{-1}$ in the sample, which was assigned to amorphous fraction of tin (IV) oxide as observed by [15].

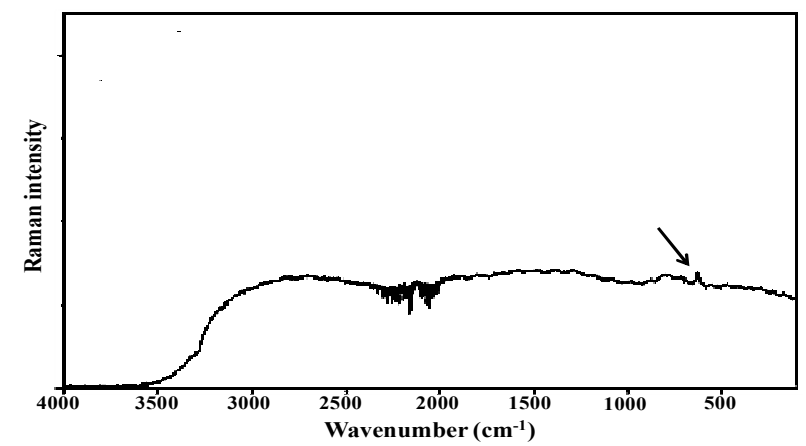

Figure 2. FT- Raman Spectrum of final stage sample of nano tin (IV) oxide obtained during the trituration of tin metal with five plant extracts followed by calcinations. (Black arrow indicates $630 \mathrm{~A}_{\text {lg }}$ mode)

\subsection{ICP-OES and CNHS Analysis}

Table 1 depicts the ICP-OES analysis of samples obtained from each stage (S1 to S5). It has been observed that there was a drastic reduction in the percentage of elemental tin. The samples of stage 1 (S1) showed $30 \%$ of Sn and upon progressing of stages; the final stage sample (S5) showed only $0.7 \%$ of Sn. It could be attributed to the maximum percentage of conversion of metallic tin to tin oxide during the preparations. The results further confirm that all the samples were free from toxic metals such as $\mathrm{Pb}$, $\mathrm{As}, \mathrm{Hg}$ and $\mathrm{Cd}$. Many elements, which are therapeutically significant in relation to the targeted diseases viz:- $\mathrm{Ca}, \mathrm{K}$, $\mathrm{Fe}, \mathrm{Mg}, \mathrm{Zn}$ were introduced at the micro level. They should have been introduced by the various herbal extracts added during each of the calcinations steps. This is in contrast to the standard tin (IV) oxide or synthetically prepared nano tin (IV) oxides which are free from the above said elements. 
Table 1. Elemental composition of the samples of nano tin (IV) oxide obtained during the trituration of tin metal with five plant extracts followed by calcinations

\begin{tabular}{|c|c|c|c|c|c|c|c|c|c|c|c|c|c|}
\hline \multirow{2}{*}{$\begin{array}{l}\text { Description of } \\
\text { the samples }\end{array}$} & \multicolumn{13}{|c|}{ Percentage weight of elements } \\
\hline & Sn & $\mathbf{C a}$ & $\mathrm{Cu}$ & $\mathrm{Fe}$ & $\mathbf{K}$ & Mg & $\mathbf{N i}$ & $\mathbf{Z n}$ & $\mathbf{S i}$ & C & $\mathbf{H}$ & $\mathbf{N}$ & $\mathbf{S}$ \\
\hline S1 & 30 & 2.90 & 0.05 & 1.25 & 5.26 & 1.14 & Nil & 0.02 & 0.71 & 5.23 & 0.93 & 0.68 & Nil \\
\hline S2 & 30.81 & 2.50 & 0.05 & 1.12 & 2.72 & 0.99 & Nil & 0.01 & 0.55 & 2.92 & 0.68 & 0.58 & Nil \\
\hline S3 & 23.87 & 2.66 & 0.04 & 1.31 & 2.97 & 1.06 & Nil & 0.03 & 0.74 & 2.48 & 0.60 & 0.09 & Nil \\
\hline S5 & 0.72 & 4.25 & 0.04 & 1.40 & 1.9 & 1.32 & Nil & 0.07 & 0.24 & 0.15 & 0.14 & 0.3 & Nil \\
\hline
\end{tabular}

The samples also demonstrated the presence of $\mathrm{C}$ and $\mathrm{S}$ in meagre percentage, as evidenced through $\mathrm{C}, \mathrm{H}, \mathrm{N}, \mathrm{S}$ elemental analysis (Table 1) and as the calcination steps proceed, only a trace level of carbon, nitrogen and sulphur along with a fractional amount of hydrogen were introduced at the final stage of the processing. It is interesting to note that despite the five trituration steps of tin metal with different herbal extracts, the contribution of organic moiety was fractional and confirmed the effectiveness of the calcination steps followed.

\subsection{Photo Luminiscence Study}

Fig. 3 depicts the photoluminescence spectrum of final stage sample. Two prominent peaks were observed at 440 and $542 \mathrm{~nm}$ when exicited at a wave length of $295 \mathrm{~nm}$. In addition, small intense peaks were also observed at 422 and $484 \mathrm{~nm}$. The peak observed at $422 \mathrm{~nm}$ may be related to the origin of photo luminescence centre created due to oxygen vacancies. The presence of structural defect as observed by [16] due to these peaks can be well correlated with that of oxide.
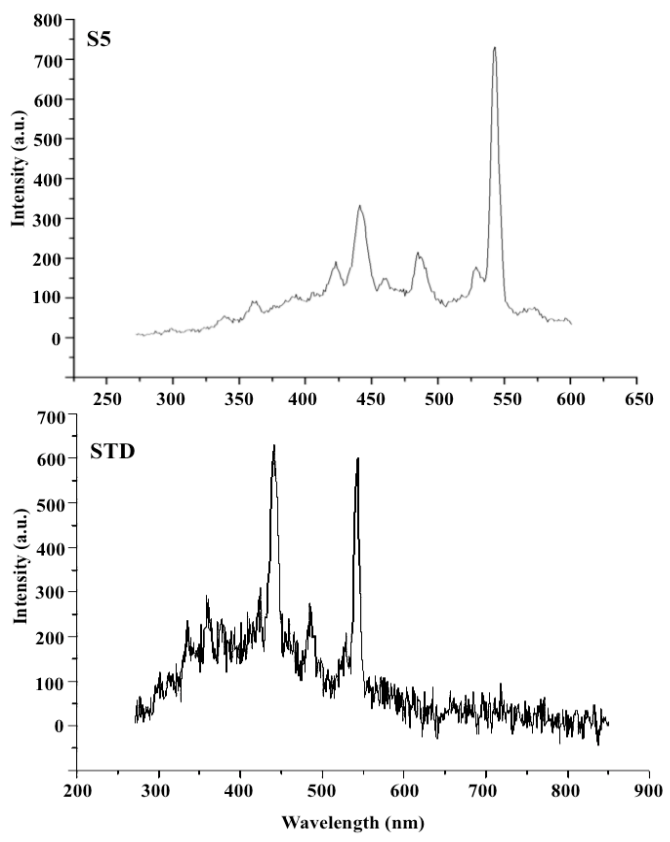

Figure 3. Photoluminescence spectra of (S5) final stage sample of nano tin (IV) oxide obtained during the trituration of tin metal with five plant extracts followed by calcinations compared with that of (STD) commercial tin (IV) oxide

\subsection{Powder X-ray Diffraction Analysis}

The PXRD spectral patterns of the samples $\mathrm{S} 1$ to $\mathrm{S} 5$ were shown in Fig. 4. The intense peak positions of each sample agreed well with the reflections of tetragonal single phase of bulk $\mathrm{SnO}_{2}$ - Casitterite -structure (ICDD 21-1250) and the absence of any other phase of tin or $\mathrm{SnO}$ and the absence of polymorphism in the final stage sample was confirmed. This observation suggested that $\mathrm{SnO}_{2}$ was the major constituent in all the samples.

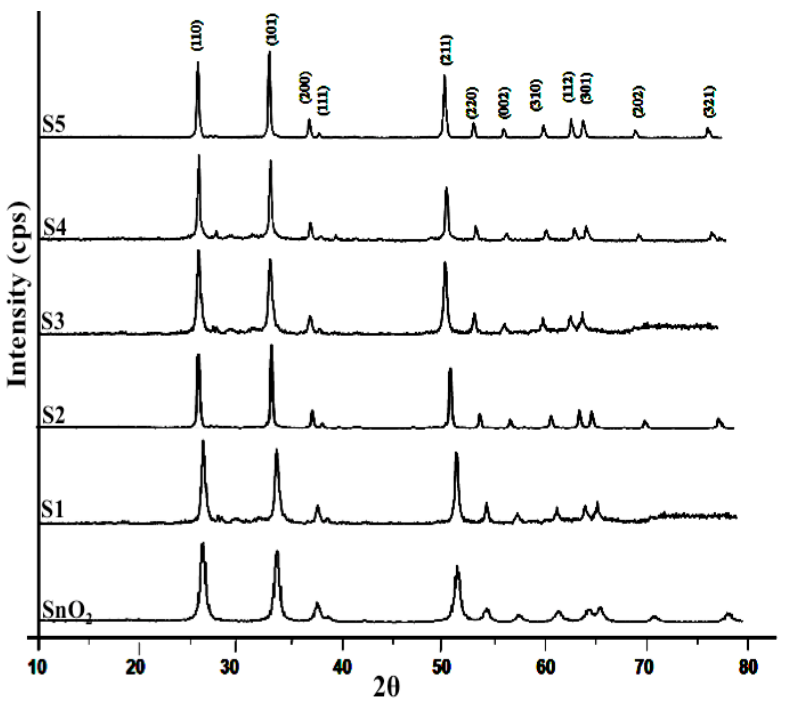

Figure 4. PXRD spectra of nano tin (IV) oxide samples obtained during the trituration of tin metal with five different plant extracts followed by calcinations

The interplanar distance ' $d$ ' values of the first and final stage sample of the nano tin (IV) oxide preparations were compared in Table 2. The formation of nano crystallites was quite evident from the broad PXRD peaks. The appearance of peaks along the phases (110), (101), (200), (220), (310), (301) and (301) with $2 \theta$ values of 26, 33, 37, $54,61,65,71$ degrees respectively also matched well with that of the chemically synthesized tin oxide reported by [17, 18,]. In the PXRD spectrum line broadening was observed and the crystallite size of the first stage and final stage sample (S1 to S5) in the most intense plane of 110, 101 was calculated by Sherrer equation as shown below after quadratic smoothening followed by Lorentian curve fitting of the peaks. 


$$
D=\frac{K \lambda}{\beta \cos \theta}
$$

where $K$ is the shape factor, $\lambda$ is the $\mathrm{X}$-ray wavelength $\left(1.5406 \mathrm{~A}^{\circ}\right), \beta$ is the line broadening at half the maximum intensity (FWHM) in radians, and $\theta$ is the Bragg angle (Patterson , 1939) , D is the mean size of the ordered (crystalline) domains, which may be smaller or equal to the grain size.

Table 2. Comparison of the ' $d$ ' values (from the PXRD analysis) of the nano tin (IV) oxide samples $S 1$ \& S5 obtained during the trituration of tin metal with five different plant extracts followed by calcinations

\begin{tabular}{llll}
\hline $\boldsymbol{h}, \boldsymbol{k}, \boldsymbol{l}$ plane & $\begin{array}{l}\text { Standard d }\left(\mathbf{A}^{\circ}\right) \text { values (ICDD) } \\
\mathbf{2 1 1 2 5 0}\end{array}$ & $\mathbf{S ~ 1}$ & $\mathbf{S 5}$ \\
\hline $1,1,0$ & 3.347 & 3.382 & 3.371 \\
$1,0,1$ & 2.642 & 2.661 & 2.690 \\
$2,0,0$ & 2.369 & 2.375 & 2.359 \\
$2,1,1$ & 1.764 & 1.770 & 1.764 \\
$2,2,0$ & 1.675 & 1.681 & 1.676 \\
$3,1,0$ & 1.498 & 1.478 & 1.484 \\
$3,0,1$ & 1.415 & 1.419 & 1.419 \\
\hline
\end{tabular}

In the present preparation, there was grinding with the herbal extract for each step. These steps would have contributed towards the formation of nano crystallites. In terms of modern technology, it is a top down approach of nano synthesis while according to [19], the long duration of grinding resulting in particle size reduction as propounded by the conventional method of size reduction. It was intended for increasing the bio availability of the components and therapeutic efficacy of the medicinal formulation. The absence of peaks due to metallic tin can also be correlated with the total conversion of metallic tin to tin oxide. These results agreed well with the ICP-OES detection of $0.7 \%$ of elemental tin. The lattice parameters obtained for the final stage sample (S5), were close to the standard tin oxide. Hence, it can be concluded that there was no doping of any element into the crystal lattice which speaks for the phase (tetragonal) homogeneity and purity of the sample. During the calcinations stages, the crystallite size varied from 29.2 to $25.7 \mathrm{~nm}$ in the 110 plane and from 34.7 to $31 \mathrm{~nm}$ in the 101 plane. There was preferential growth in the 101 plane as indicated by the intensity of the peak. Even though the number of calcinations steps was five, there was size stabilisation at the final stage due to the presence of calcium ions.

\subsection{EPR Spectral Analysis}

The EPR spectra of the final stage sample S5 measured at room temperature. Fig. 5 showed a broad peak and there was a interaction of both metal and oxygen with the microwave radiation. The signal was strong and hence there is a possibility of good amount of paramagnetic species.
The ' $\mathrm{g}_{\|}$' value of 2.759 and $\mathrm{g}_{\perp}$ was found to be 2.022 and suggested the non-stoichiometry present in tin (IV) oxide with singly ionized oxygen vacancies accounting for the paramagnetic property in agreement with the observations of [20].

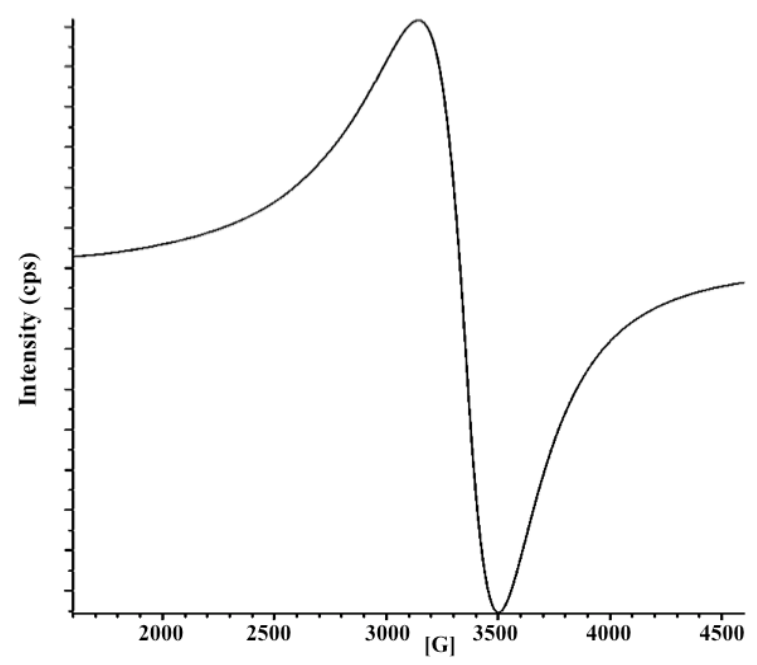

Figure 5. EPR Spectrum (at room temperature) of final sample of nano tin (IV) oxide obtained during the trituration of tin metal with five different plant extracts followed by calcinations.

\subsection{Thermo Gravimetric Analysis}

The thermograms of the samples $\mathrm{S} 1$ to $\mathrm{S} 5$ were given in Fig. 6. About $8 \%$ weight loss between 200 and $600^{\circ} \mathrm{C}$ was observed for $\mathrm{S} 1$ could be attributed to the decomposition of organic matter as evidenced from the FTIR spectrum. Samples S2, S3 and S4 displayed only 4\% weight loss and could be attributed to the physisorbed moisture. In the final stage sample (S5) there was no change in weight loss till $750{ }^{\circ} \mathrm{C}$ and suggested the thermal stability [21].

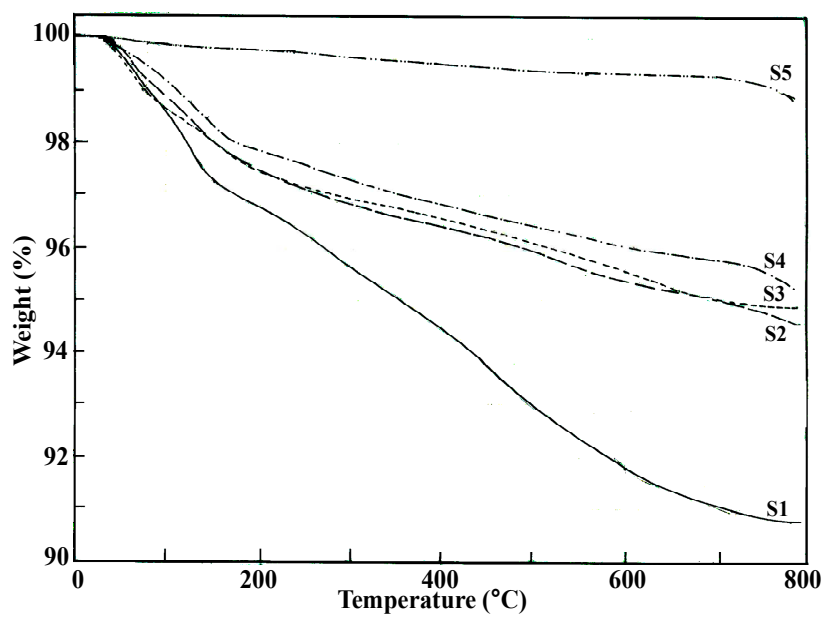

Figure 6. Thermo gravimetric analysis of samples of nano tin (IV) oxide obtained during the trituration of tin metal with five different plant extracts followed by calcinations 


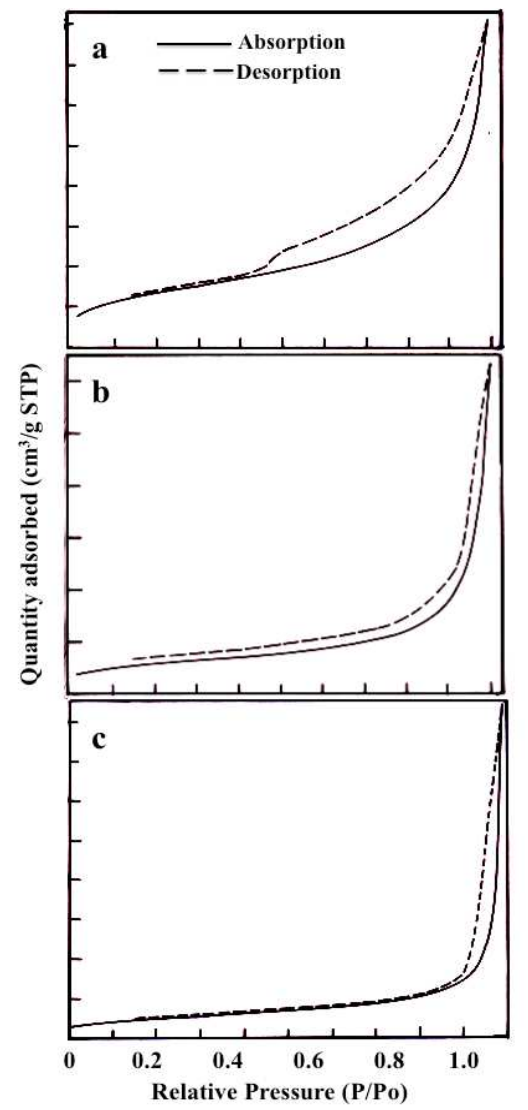

Figure 7. BET isotherms of a: Stage 1 (S1) sample. b: Stage 5 (S5) sample of nano tin (IV) oxide obtained during the trituration of tin metal with five different plant extracts followed by calcinations and c: Standard tin oxide sample

\subsection{BET and BJH Pore Analyses}

BET isotherm studies were carried out for the initial and the final stage samples S1 and S5. Table 3 compares the stage I and stage 5 of the nano tin (IV) oxide samples and Fig. $7 \mathrm{a}$ and Fig. $7 \mathrm{~b}$ illustrates the BET isotherm of stage 1 sample and final stage sample respectively. For S1 sample, BET isotherm corresponds to Type IV isotherm based on the IUPAC recommendations (1985) and there was a hysteresis loop associated with the capillary condensation taking place in mesopores. This type of isotherm can also be correlated with a higher BET surface area and nano crystallites compared to standard bulk tin (IV) oxide.

For the final stage sample S5, Type II BET isotherm was observed. The curve was first concave to the $\mathrm{P} / \mathrm{P}_{0}$ axis and then almost linear and finally convex to the $\mathrm{P} / \mathrm{P}_{0}$ axis. It indicated the formation of an adsorbed layer whose thickness increases progressively with increasing relative pressure until $\mathrm{P} / \mathrm{P}_{0} \rightarrow 1$.Similar observations were made with commericially available standard tin oxide (Fig. 7c).

Table 3 illustrated the BET surface area and grain size of samples of S1and S5 and standard tin oxide. The average particle diameter in nanometre was calculated from the following formula;

$6000 /\left(\right.$ BET surface area in $\left.\mathrm{m}^{2} / \mathrm{g}\right) \times\left(\right.$ density in $\left.\mathrm{g} / \mathrm{cm}^{3}\right)$

There was a steep decrease in the BET surface area of the sample from first stage to the final stage in relation to their crystallite size calculated from PXRD. The presence of aggregates with inclusion of other elements getting into the surface as can be correlated with the SEM.

Table 3. Comparison of grain size and crystallite size (from the PXRD analysis) for sample S1 \& S5 of nano tin (IV) oxide obtained during the trituration of tin with five different plant extracts followed by calcinations

\begin{tabular}{lllll}
\hline Sample & $\begin{array}{l}\text { Average crystallite } \\
\text { in } \mathbf{~ s m}\end{array}$ & size surface area $\mathbf{~ m}^{2} / \mathbf{g}$ & Grain size in $\mathbf{~ m m}$ & $\begin{array}{l}\text { Cumulative pore volume } \\
\mathbf{c m} 3 / \mathbf{g}\end{array}$ \\
\hline $\mathrm{S} 1$ & 29 & 9.1665 & 94.181 & 0.0253 \\
$\mathrm{~S} 5$ & 37 & 3.8862 & 222 & 0.0193 \\
Standard $\mathrm{SnO}_{2}$ (present study) & $>50$ & 8.529 & 101 & 0.0100 \\
\hline
\end{tabular}

The BJH pore size distribution as shown in Fig. 8a8 b.The cumulative pore volume and pore area were found to be $0.015 \mathrm{~cm}^{3} / \mathrm{g} 0.0253 \mathrm{~m} 2 / \mathrm{g}$ for $\mathrm{S} 1$ and for S5 sample. The pore distribution was wide as can be seen in the figure which reflects in the adsorption capacity of the final sample.

$\mathrm{BJH}$ pore radius varied over a wide range from 9.7 to $203 \mathrm{~A}^{\circ}$ and $10.4 \mathrm{~A}^{\circ}$ to $174 \mathrm{~A}^{\circ}$ for $\mathrm{S} 1$ and $\mathrm{S} 5$ samples respectively. This technique characterises pore size distribution independent of external area due to particle size of the sample. The surface morphology as predicted by the above techniques was correlated with Transmission Electron Microscopic (TEM) images of the samples.

\subsection{Scanning Electron Microscopic Images}

The shape, size, morphology of the nano crystallites determine their applications in the field of electronics, medicine, chemical industry.[22]; The surface morphology of the samples S1 to S5 as depicted in Fig. 9. In the SEM images, the initial stage sample $\mathrm{S} 1$, showed small particles with grain boundaries, which also correlated well with the BET surface area report. Further stages of calcinations brought more agglomeration leading to bigger particle size in stages 2, 3, and 4 with relatively lesser crystallinity. In the final stage sample S5, there was disintegration of bigger crystallite particles so that there was distribution of various sizes of particles. The grain size of the samples as shown in the figure is in the order of micrometer suggestive of the agglomeration of nano sized crystallites formed 


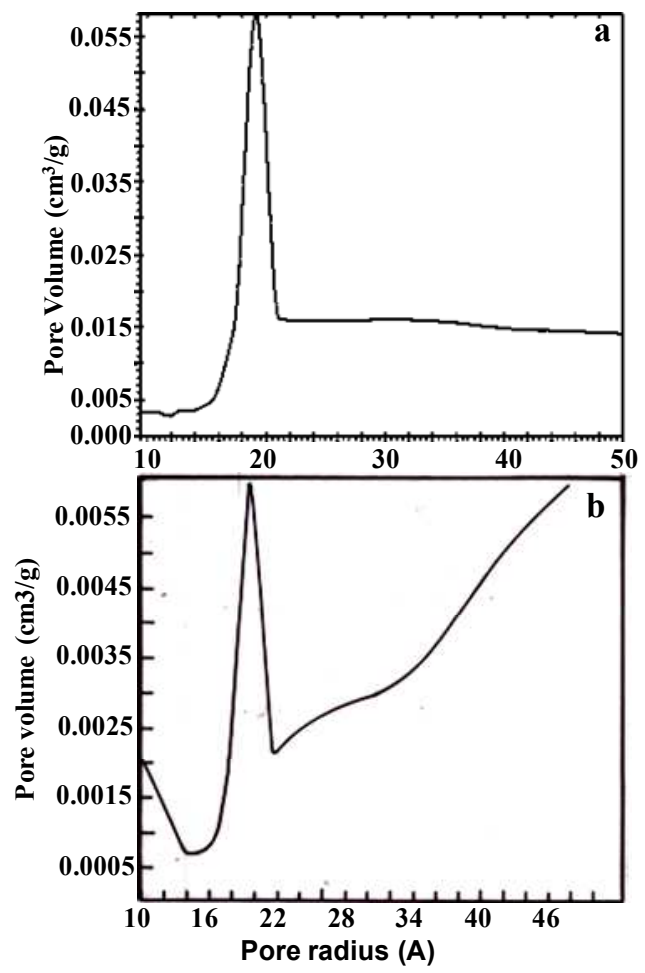

Figure 8. BJH pore volume distribution of sample $S 1$ (a) and S5 (b) of nano tin (IV) oxide obtained during the trituration of metallic tin with five different plant extracts followed by calcinations
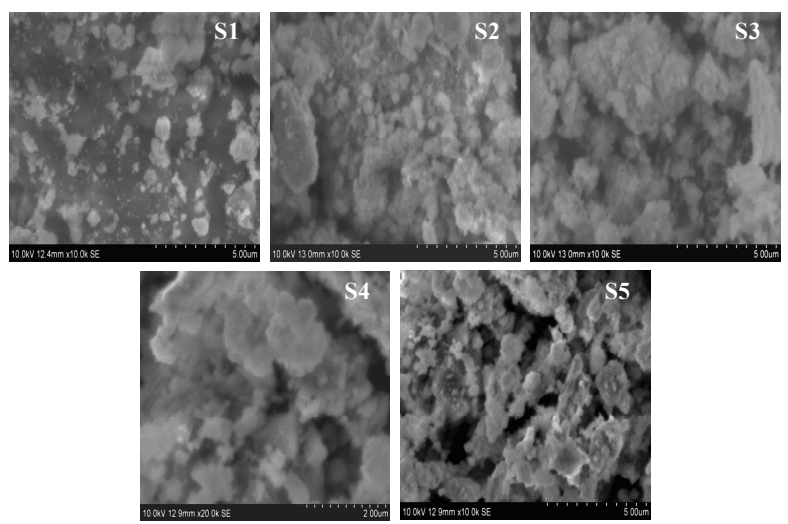

Figure 9. SEM images of $S 1, S 2 S 3, S 4$ and S5 stage samples of nano tin (IV) oxide obtained during the trituration tin metal with five different plant extracts followed by calcinations

\subsection{Transmission Electron Microscopic Image}

The TEM image of the fifth (final) stage sample Fig.10 indicated the presence of particles being composed of aggregates of irregular spherical crystallites. It was also indicative of the presence of bigger grains composed of the nano crystalline domains due to repeated calcinations The surface composition as can be seen from the TEM image of the final stage sample showed the presence of elements of Calcium and Phosphorous, even though presence of Iron, Potassium, Magnesium were indicated by the ICP-OES results. There was oxygen deficiency indicative of nonstoichiometric defect in the crystal lattice.

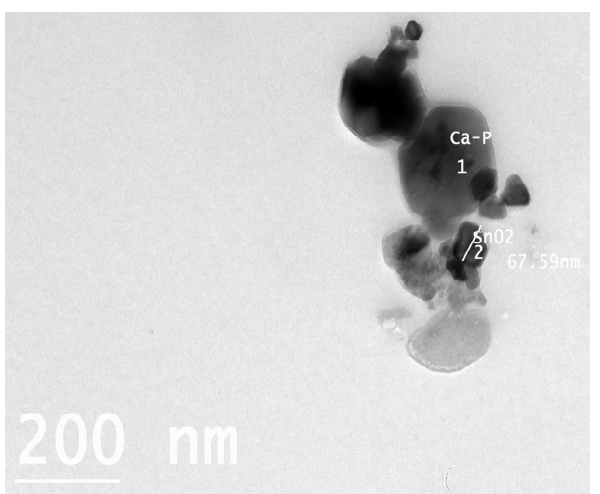

Figure 10. TEM image of S10 stage (Final stage) sample of nano tin (IV) oxide obtained during the trituration of tin metal with five different plant extracts followed by calcinations

\subsection{X-ray Photoelectron Spectroscopic Analysis}

According to [23], the surface state of the particles is determined by the type of calcinations process viz: presence of air, oxygen or any other carrier gas and the size of the crystallite is affected by the presence or absence of carrying gas. In the present study, the chemical state of tin and oxygen at the surface were examined by XPS. Fig.11 shows Sn 3d regions, $\mathrm{O}(1 \mathrm{~s})$ and wide scan of the samples S1, S3, S5 respectively.

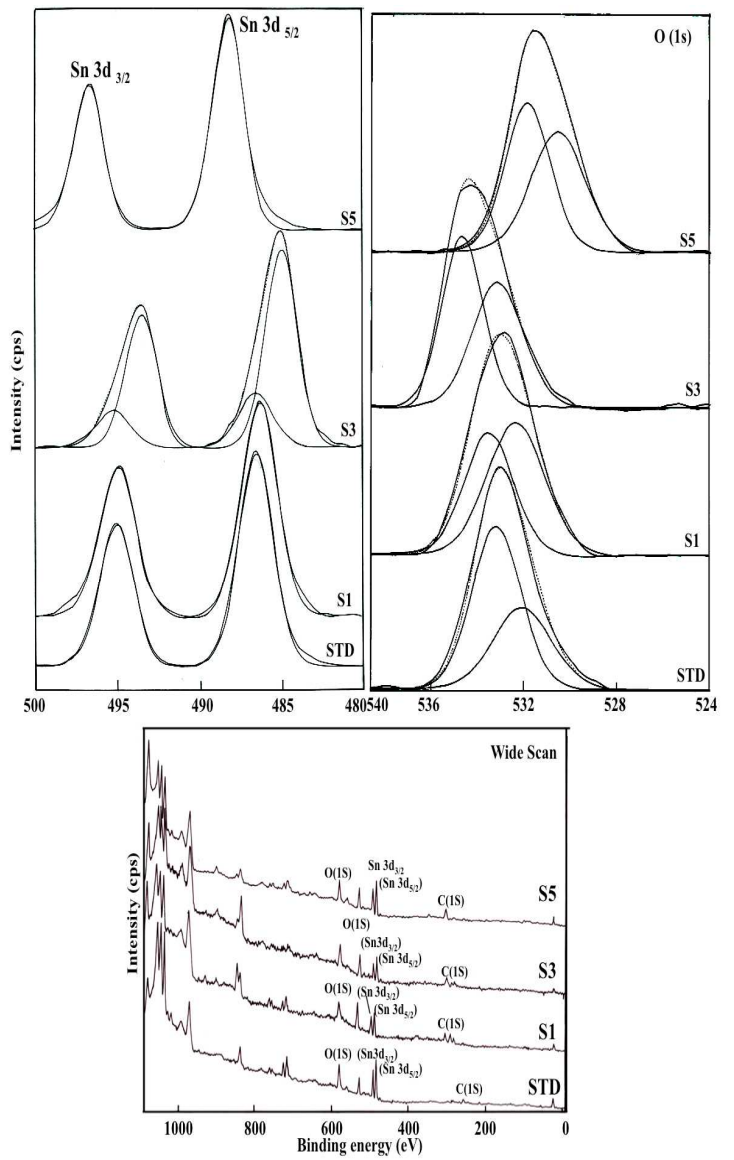

Figure 11. XPS spectrum, Binding energy curve of $\operatorname{Sn}(3 d 3 / 2 \&$ \&n $3 d 5 / 2$ $O(1 s)$ and wide scan of $S 1, S 2, S 3, S 4 \& S 5$ stage samples of nano tin (IV) oxide obtained during the trituration of tin metal with five plant extracts followed by calcinations 
Usually, O (1s) peak has been observed in the binding energy region of 529 to $535 \mathrm{eV}$ with the peak from 529 to $530 \mathrm{eV}$ which is attributed to lattice oxygen [24] attributed the peak in the region $530.7-531.6 \mathrm{eV}$ to oxygen in non stoichiometric oxides and the peak around $533 \mathrm{eV}$ to a weakly bound surface oxygen.

Table 4. Elemental composition and binding energy values observed from XPS spectrum for stage1(S1)and stage5 (S5) samples of nano tin (IV) oxide obtained during the trituration of tin metal with five different plant extracts followed by calcinations

\begin{tabular}{lll}
\hline Sample & Element & Binding energy (eV) \\
\hline Bulk $\mathrm{SnO}_{2}$ & $\mathrm{Sn}\left(3 \mathrm{~d}_{5 / 2}: 3 \mathrm{~d}_{3 / 2}\right)$ & $486.6: 495.0(\Delta=9.4)$ \\
$\mathrm{S} 1$ & $\mathrm{Sn}\left(3 \mathrm{~d}_{5 / 2}: 3 \mathrm{~d}_{3 / 2}\right)$ & $486.4: 494.8(\Delta=8.5)$ \\
$\mathrm{S} 3$ & $\mathrm{Sn}\left(3 \mathrm{~d}_{5 / 2}: 3 \mathrm{~d}_{3 / 2}\right)$ & $486.0: 495.2(\Delta=10.2)$ \\
$\mathrm{S} 5$ & $\mathrm{Sn}\left(3 \mathrm{~d}_{5 / 2}: 3 \mathrm{~d}_{3 / 2}\right)$ & $488.2: 496.8(\Delta=(8.6)$ \\
Bulk SnO & $\mathrm{O}(1 \mathrm{~s}) \mathrm{lattice}_{2}$ adsorbed & 530.8 and 531.9 \\
S1 & $\mathrm{O}(1 \mathrm{~s})$ & 530.5 and 531.6 \\
S3 & $\mathrm{O}(1 \mathrm{~s})$ & 529.9 and 530.9 \\
S5 & $\mathrm{O}(1 \mathrm{~s})$ & 532.2 and 533.5 \\
\hline
\end{tabular}

The binding energy values are sensitive to the covalent character of the metal oxygen bond and we observed a increase in both the $\mathrm{Sn}(3 \mathrm{~d})$ and $\mathrm{O}(1 \mathrm{~s})$ binding energy levels compared to the bulk tin oxide indicating smaller covalency and the absence of more electropositive elements.

\subsection{Antioxidant Profile Using EPR Spectra}

For antioxidant profiling of the sample, the free radical quenching behaviour was assessed using EPR spectroscopy. The free radical equivalent of $\mathrm{DPPH}^{\circ}$ of the sample was calculated. The free radical equivalent of DPPH per mg of the sample was calculated as 0.8026 . The result can be correlated with the capability of the product for medical purposes. In the present study the anti oxidant property of tin (IV) oxide present with the free radical quenching factor could play a major role in the antimicrobial property. It can also be correlated with the anti oxidant property of titanium oxide (also having tetragonal structure similar to tin oxide), which was responsible for the degradation of Reactive Oxygen Species (ROS) with immediate inflammatory response as observed by ${ }^{[25]}$ Contreras et al (2007). The plant extracts provided alkaloids, cyclopeptides, flavanoids, phenols, tannins and minerals like $\mathrm{Cu}, \mathrm{Fe}, \mathrm{Mn}, \mathrm{Zn}, \mathrm{Se}$ which could have contributed towards therapeutics or a secondary effect for the anti oxidant property.

\section{Conclusion}

The research study provided a new top down approach for the synthesis of nano composite of tin (IV) oxide with multi dimensional applications. There was a natural inclusion of significant elements like $\mathrm{Ca}, \mathrm{Mg}$ giving a unique surface of the nano crystalline tin (IV) oxide in the parlance of modern nanotechnology. The impact of grinding with plant extracts repeatedly not only to reduce the particle size but also improved the bio availability. The analytical results of the study also clearly indicated the formation of nano crystallites of tin oxide with increasing crystallinity and preferred orientation in the (101) plane with proceeding steps of grinding and calcinations. The process provided a technique of preparing a multifunctional nano tin (IV) oxide with unique bulk and surface property.

\section{Competing Interests}

The authors declare that they have no competing interests.

\section{Acknowledgement}

The author S.Sudhaparimala is thankful to the University Grants Commission, Govt. of India and Ethiraj College for Women, Chennai, India, for the award of UGC-FIP fellowship under the XI Plan. The author is also grateful to IIT Madras for providing the instrumental facilities.

\section{References}

[1] Radha Narayanan, "Synthesis of green nanocatalysts and industrially important green reactions," Green Chemistry Lett. and Rev. 5(4) : 707-725,2012.

[2] S.R.Bonde, D.P.Rathod, A.P. Ingle, R.B. Ade, A.K. Gade , M.K. Rai, ".Murraya koenigii-mediated synthesis of silver nanoparticles and its activity against three human pathogenic bacteria, " Nano Sci methods, 1(1)1:25-36, 2012

[3] K.S.Kavitha, S.Baker, D.Rakshith, H.U. Kavitha, B.P. Harini, \& S.Satish, "Plants as Green Source towards Synthesis of Nanoparticles". Int. Res.J. Biological Sci, 2(6), 66-7, 2013.

[4] Feng Gu, Shu Fen Wang, Meng Kai Lu, Guang Jun Zhou, Dong $\mathrm{Xu}$, Duo Rong Yuan, "Photoluminiscence properties of $\mathrm{SnO}_{2}$ Nano particles Synthesised by Sol - Gel Method, "J.Phy. Chem. B 108, 8119-8123, 2004.

[5] J.Trigilio, T.E.Antoine, I. Paulowicz , Y.K.Mishra, R.Adelung, " Tin Oxide Nanowires Suppress Herpes Simplex Virus-1 Entry and Cell-to-Cell Membrane Fusion". PLoS ONE 7(10), 2012.

[6] S.S.Parimala, A.Gnanamani , A.B. Mandal, “ Bulk and surface properties of tin based herbal drug during its preparation: fingerprinting of the active pharmaceutical constituent," Int. J. Pharm. Sci. and Res. 3(4): 1037-1042, 2012.

[7] S.Sudhaparimala, A. Gnanamani, A.B.Mandal, "Egg shell powder as the Precursor for the Synthesis of nano crystalline Calcium Stannate (CaSnO3) with Orthorhombic Perovskite structure: Exploration on Phase, Morphology and Antioxidant property". Che Sci Rev Lett , 2(5), 267-277, 2012. 
[8] K.M. Nadkarni, "Indian Materia Medica,". 3th edition. Mumbai: Popular Prakashan Ltd., 1062-1063, 1976.

[9] Julio César Escalona-Arranz, Renato Pérez-Rosés, Irina Licea Jiménez, Jesús Rodríguez-Amado, Humberto ArgotaCoello, Javier Cañizares-Lay, Humberto, "Chemical constituents of Tamarindus indica L. LEAVES,” J. Revista Cubana de Quimica,Morris-Quevedo, Gustavo SierraGonzález XXII : 3, 2010.

[10] Hassan Abdalla Almahy and Nafisa Ibrahim Alhassan, "Studies on the Chemical Constituents of the Leaves of Ficus Bengalensis and Their Antimicrobial Activity, “ J.Sc. Tech - 12(1), 2011.

[11] Arumugam Kathirvel and Venugopal Sujatha, "Phytochemical analysis and antioxidant activity of barringtonia acutangula (1) gaertn. Leaves," Int J Pharm Pharm Sci, 4(2), 277-281, 2012.

[12] Neha Pandey, Dushyant Barve , "Phytochemical and Pharmacological Review on Annona squamosa Linn International Journal of Research in Pharmaceutical and Biomedical Sciences, “Vol. 2(4) Oct - Dec 2011.

[13] A.K. Chudiwal, D.P. Jain, R.S Somani, "Alpinia galanga Willd - An overview on phyto-pharmacological properties," Indian J Nat Prod Resour. 1(2), 143-149,2010.

[14] K.Nakamato, "Infrared and Raman spectra of inorganic and coordination compounds, "New York: John Wiley and Sons, 1, 978-226, 1986.

[15] M. Ristic, I.M., Popovic, S.Music, "Dependence of nano crystalline $\mathrm{SnO}_{2}$ particle size on synthesis route". J Non Crystalline Solid, 303, 270-280, 2002.

[16] S.Chacko, N.S.Philip, K.G.Gophandran, P.Koshy, V.K. Vaidyan, "Nanostructural and surface morphological evolution of chemically sprayed $\mathrm{SnO} 2$ thin films," Appl. Surf. Sci. 254:2179-2186, 2008.
[17] ICDD. Powder diffraction file, edited by S. Kabekkodu, International Centre for Diffraction Data, Newtown square, Pennsylvania, 21-1250 Tetragonal crystallographic system Space group P4 /mnm (136), 2009.

[18] S.Sudhaparimala, Christina Selin, A.Gnanamani, A.B.Mandal, "Synthesis and characterisation of nano crystalline tin (IV) oxide from tin (II) chloride using combined microwave and traditional calcinations procedures". J Cur Res. in Che.4: 60-67, 2012.

[19] V.Thangadurai, A.K.Shukla, J.Gopalakrishnan, "Proton conduction in layered perovskite oxides," Solid State Ionics , 73 (1-2) : 9-14, 1994.

D.L.Ningthoujam, V.Sudarsan, H.K.Poswal, S.K.Kulshreshtha, S.M.Sharma, B.Bhushan, M.D.Sastry," Nature of $\mathrm{V} \mathrm{n}+$ ions in $\mathrm{SnO} 2$ : EPR and Photoluminescence studies”. Mat Res Bul, 42,1293-1300, 2010.

[20] Gabbott Paul, Principles and applications of thermal analysis. Blackwell Publishing Ltd. 2008.

[21] D.H.Gracias, J. Tien, T.Breen, C. Hsu, G.M. Whitesides, "Forming electrical networks in threedimensions by self assembly," Science, 289,1170-1172, 2000.

[22] Mariana Ionita, loan Vorl Branzoi, Laurentiu Popa, "Synthesis, physicochemical characterization, and preliminary molecular modelling studies on $\mathrm{SnO}_{2}$ nanoparticles,” Surf. Inter. Anal. 42, 983-986, 2009.

[23] I.S.Mulla, V.J., Rao, H.S. Soni, S. Badrinarayanan, A.P.B. Sinha, A.P.B, "Electron spectroscopic studies on films of $\mathrm{SnO} 2$ and $\mathrm{SnO}_{2}$ : Sb", Surf. Coat Tech. 31, $77-88,1987$.

[24] .R.Contreras, H. Sahlin, H, J.A.Frangos, "Titanate biomaterials with enhanced anti inflammatory properties," J Biomed Mater Res A, 80A, 480-485, 2007. 